\title{
The development of a return to work intervention programme for stroke survivor (SReTWIP): a Delphi survey
}

Olumide Ayoola Olaoye ${ }^{1,2^{*}}$, Shaheed Moghammad Soeker ${ }^{1}$ and Anthea Rhoda ${ }^{3}$

\begin{abstract}
Background: Even though clearly defined pathways for vocational re-entry are well recognized for conditions such as mental health, musculoskeletal dysfunction (MSD) and traumatic brain injury (TBI), none has been identified for stroke. There has been a lack of consensus regarding such clear pathways to vocational re-entry and the essential contents of return to work (RTW) interventions for stroke survivors. As part of a larger study aimed to design a RTW programme for stroke survivors, this study describes the concluding process through which Stroke Return to Work Intervention Programme (SReTWIP) was developed.

Methods: Experts in the field of neurorehabilitation and vocational rehabilitation (VR) from 6 countries participated in this 3-round Delphi survey via e-mail. Concept mapping was used to triangulate findings from the Delphi with previous phases of the larger study. Content thematic analysis was conducted on qualitative data while descriptive statistic was used to analyze quantitative data.

Results: Fifteen experts with a mean age and mean duration of practice of $44.73 \pm 9.48$ years and $18.26 \pm 8.71$ years respectively participated in this study. The developed RTW programme (SReTWIP) is a 12 week programme that consisted of four interconnected phases of intervention viz: an assessment phase, clinic-based work and non-work specific intervention phase, a work test placement phase and a client full participation in worker role phase. The experts agreed on a set of implementation strategies that included the use of interdisciplinary team, the tailoring of intervention to meet stroke survivor's need, as well as the use of case management approach.

Conclusion: The SReTWIP is the first step in developing a VR pathway that can ultimately enhance the RTW rates and quick resumption of the worker role of stroke survivors. The stroke survivor can move along the different phases of the SReTWIP after achieving competency in a preceding phase. Future work will include a feasibility study with other key stakeholders involved in RTW such as employers, informal caregivers and stroke survivors before its implementation.
\end{abstract}

Keywords: Stroke, Vocational rehabilitation, Return to work, Intervention, Programme, Cerebrovascular accident

\footnotetext{
* Correspondence: mideolaoye@gmail.com

'Departments of Occupational Therapy, Faculty of Community and Health Sciences, University of the Western Cape, Cape Town, South Africa

${ }^{2}$ Departments of Medical Rehabilitation, College of Health Sciences, Obafemi Awolowo University, Ile-lfe, Nigeria

Full list of author information is available at the end of the article
}

(c) The Author(s). 2020 Open Access This article is licensed under a Creative Commons Attribution 4.0 International License, which permits use, sharing, adaptation, distribution and reproduction in any medium or format, as long as you give appropriate credit to the original author(s) and the source, provide a link to the Creative Commons licence, and indicate if changes were made. The images or other third party material in this article are included in the article's Creative Commons licence, unless indicated otherwise in a credit line to the material. If material is not included in the article's Creative Commons licence and your intended use is not permitted by statutory regulation or exceeds the permitted use, you will need to obtain permission directly from the copyright holder. To view a copy of this licence, visit http://creativecommons.org/licenses/by/4.0/ The Creative Commons Public Domain Dedication waiver (http://creativecommons.org/publicdomain/zero/1.0/) applies to the data made available in this article, unless otherwise stated in a credit line to the data. 


\section{Background of the study}

Over the past decades, there has been growing concern on the increasing incidence and prevalence of stroke and its attendant high morbidity in developing countries [1, 2 ]. Arising from acute focal or global injury to the central nervous system by a vascular cause, stroke could result in considerable neurological deficits on its survivor [2]. After a stroke, significant number of survivors experience prolonged work absence that render them unproductive within the community. Meanwhile, it is documented that RTW after prolong work absence due to ill health requires a well-defined VR pathway $[3,4]$. This had resulted in emergent interest in the application of evidence-based RTW interventions for work disability management for various health conditions. For instance, supported employment programme and model of occupational self-efficacy are evidence-based VR programmes that have over the years been used to facilitate work integration for individuals with serious mental illness and TBI respectively [5, 6]. Even though clearly defined pathways for vocational re-entry are well recognized for chronic conditions such as mental health, MSD and TBI [5-7], none has been identified for stroke as there has been a lack of consensus regarding such clear pathways to vocational re-entry. Similarly, no validated evidence has been established for the essential contents of RTW interventions needed to effectively facilitate work reintegration for the individuals that have experienced stroke. More specifically, in Nigeria which serve as the study context, there is a gap in the strategies to facilitate work re-entry for stroke survivors. Although, mental illness, MSD and TBI are chronic conditions, stroke is an acute disease with a potential chronic sequelae that influences work functioning. As part of a larger study aimed to design a RTW programme for stroke survivors, a preliminary study (Study I) on need assessment and identification of performance objective was conducted [8]. The study surveyed 210 stroke survivors in south-west, Nigeria using the Work Rehabilitation Questionnaire, the International Classification of Functioning, Disability and Health (ICF) Brief Core Sets for VR and the Work Impact Questionnaire to establish baseline data on the impairments, activity limitation and participation restrictions experienced by stroke survivors, as well as their RTW rates [8]. The study found that more than a third of stroke survivors did not RTW as a result of the sequelae of stroke while only half of the survivors that RTW did so at a reduced capacity (part-time and light duty). Similarly, the above study discovered patterns across marital status, disability level, work category and workplace support in how stroke survivors RTW. While identifying the performance objectives that were needed to facilitate RTW of stroke survivors in the same study, it was established that the side of stroke affectation, type of rehabilitation programme, stroke symptoms, environmental factor as well as problem experienced by survivors in activity and participation could significantly predict RTW capacity of stroke survivors. It was also found that work resumption after stroke was influenced by the recovery of functional abilities of the survivor; access to rehabilitation services; workplace directed interventions; as well as self-determination of the stroke survivor to RTW.

Similarly, as part of the larger study, a review of literature (Study II) was conducted to identify effective RTW interventions for stroke survivors [9]. The above study reviewed 32 articles and one clinical guideline from nine databases and grey literature that transverse 11-year period using the Arskey and O'Malley scoping review methodology [10]. The reviewed studies vary in terms of rationale, methodology design, description of intervention activities, and period of deployment and delivery mode of interventions. Three core components of RTW interventions that included intervention components that interfaced with the stroke survivor, intervention components that interfaced with the workplace and, implementation strategies were identified [9].

In order to arrive at a consensus regarding the RTW intervention components that are essential and to define a clear vocational pathway for implementing such RTW components when replicating effective interventions, this final stage of the study was conducted. This study describes the process through which the SReTWIP was developed.

\section{Methods}

For the development of the SReTWIP, the authors used a multi-phase mixed method research approach that was guided by Intervention Mapping framework [11]. This comprised three iterative studies that informed one another with the findings culminating into the SReTWIP. The concluding study (Study III-Delphi survey) which attempts to identify the essential components of RTW intervention and to define a clear vocational pathway for implementing such RTW components when replicating effective interventions is described in this manuscript. Delphi survey $[12,13]$ is a recognized consensus formation method which involves the achievement of consensus among a group of experts via series of survey. While the first survey is usually open ended, the subsequent surveys are shaped by the results of the prior ones. A modified e-Delphi survey was utilized in this study The modification to the e-Delphi entailed merging of the opinion of experts from the first round of the Delphi with evidences from the previous studies $[8,9]$ for further controlled feedbacks in the subsequent rounds of the Delphi process. The participants were experts in the field of neuro-rehabilitation and VR involved in the 
RTW process of stroke survivors. They were purposively selected from healthcare circle and academia.

\section{Delphi rounds}

A peculiar feature of the Delphi survey is the multiple iterations that entail a series of feedback processes which allow experts to review their opinions on a topic [14]. In the present study, the e-Delphi survey consisted of three rounds conducted over a 6 month period. Consensus was reached at the end of the third round of the eDelphi.

\section{Selection of experts}

In order to capture diverse knowledge and opinion pertaining to RTW interventions for stroke survivors, the Delphi selection process described by Okoli and Pawloski [15] was used to purposively select 29 experts comprising occupational therapists (OT), physiotherapists (PT), and clinical psychologists who were familiar with the Nigerian health context. Experts without prior knowledge of the study context were provided with adequate information to guide with decision making during the survey.

\section{Procedure}

The Research Ethics and Higher Degrees Committee of the University of the Western Cape, South Africa as well as the Health Research and Ethics Committee of the Institute of Public Health, Obafemi Awolowo University, Nigeria, gave approval for this study. Online invitation, consent and information sheet was sent out to 29 selected experts. Eighteen of the experts initially provided written consent to participate with three later recusing themselves for lack of adequate knowledge on the topic of interest. No reason was given by the other experts who declined to participate in the study. Consenting experts responded to an online questionnaire that sought information on their demographic profile. The first round of the survey spanned 4 weeks during which 15 experts provided answers to four open ended questions regarding interventions that were needed to facilitate RTW of stroke survivors. At the end of the first round, opinions were collated and analyzed. Results obtained were triangulated with findings from the previous phases (Study I and Study II) of the study into an initial concept map that was later transformed into a draft SReTWIP. The second round entailed presenting the draft SReTWIP to the experts to rate its feasibility on a three point nominal scale of disagree; indifferent; and agree. They were also requested to provide further input on the content and structure, components, approaches, implementation strategies and duration of implementation of the programme. In the third round, questions without consensus were reviewed base on input from experts and pulled into a questionnaire which was sent back to the experts. These included items that had between five to eight experts that agreed to their inclusion and less than 5 experts that agreed to their exclusion.

They were requested to indicate the appropriateness of the revisions made to the intervention contents using binary options. Base on the suggestions provided by the experts, the duration of the phases of intervention was reviewed and divided into 'how long' (timing) and "how often" (the numbers of sessions required). To be eligible for inclusion in the SReTWIP, consensus was set at $69 \%$ and above for the second and third rounds. The experts were thereafter notified of the completion of the final round of the Delphi and provided with a copy of the developed SReTWIP.

\section{Data analysis}

The data obtained from the first round of the Delphi survey was analyzed thematically using the procedure described by Corbin and Strauss [16]. The quantitative responses from the experts in the second and third round were analyzed descriptively using means of central tendency and percentages.

\section{Results}

The mean age and mean duration of practice of the experts was $44.73 \pm 9.48$ and $18.26 \pm 8.71$ years respectively. The demographic characteristics of the experts is summarized in Table 1 . Three major themes emerged from the responses of the panel (Table 2). The concept map developed from the triangulation of findings from the previous two phases of the study is presented in Fig. 1. Five key areas contributed to the development of the SReTWIP into a deliverable and coherent RTW programme viz.: programme structure, participants, theories, context, and focus. The draft SReTWIP is presented in Table 3. The SReTWIP comprised four phases namely: an assessment phase (phase 1), a Work Intervention Training (WIT) phase (phase 2), Work Test Placement (WTP) phase, and the Clients Full Participation in Worker Role phase. The response rate to the second round Delphi was $86.7 \%$ as two experts who participated in the first round did not respond to the second round survey. The experts $(n=13,100 \%)$ agreed that the structure and content of the SReTWIP should include work specific training and WTP phase while majority agreed that assessment $(n=10,76.92 \%)$, non-work specific intervention $(n=11,84.62 \%)$ and clients full work participation ( $n=12,92.31 \%)$ should be included. The experts however advised that the assessment phase should include goal setting and more of functional capacity evaluation that is conducted at the workplace compared to the use of work samples. Similarly, the experts suggested that stroke survivors' self-awareness of 
Table 1 Demographic characteristics of panel of experts

\begin{tabular}{|c|c|c|c|c|c|c|c|c|}
\hline$\overline{I D}$ & Age & Sex & Qualification & Country of Practice & Current Occupation & $\begin{array}{l}\text { Years of } \\
\text { Experience }\end{array}$ & $\begin{array}{l}\text { Years of experience } \\
\text { in SRNR }\end{array}$ & $\begin{array}{l}\text { Roles in SR } \\
\text { and stroke VR }\end{array}$ \\
\hline 1 & 52 & Male & M.Sc. & Nigeria & Clinical psychologist & 27 & 17 & $A, I, M / F$ \\
\hline 2 & 55 & Male & D.ClinPsy & UK & Neuropsychologist & 31 & $20+$ & $\mathrm{A}, \mathrm{I}, \mathrm{MF}$ \\
\hline 3 & 39 & Female & M.Sc. & Nigeria & Consultant OT (private practice) & 14 & 6 & $A, I, R$ \\
\hline 4 & 33 & Male & M.Sc. & Nigeria & OT clinician & 7 & 7 & $\mathrm{~A}, \mathrm{I}, \mathrm{CM}, \mathrm{MF}$ \\
\hline 5 & 31 & Male & M.Sc. & UK & OT clinician & 10 & 8 & $\mathrm{~A}, \mathrm{I}, \mathrm{CM}$ \\
\hline 6 & 37 & Male & M.Sc. & Nigeria & OT clinician & 13 & 10 & $\mathrm{~A}, \mathrm{l}, \mathrm{MF}$ \\
\hline 7 & 41 & Male & M.Sc. & Canada & OT clinician & 16 & 10 & $A, I$ \\
\hline 8 & 45 & Female & Ph.D. & South Africa & Academia (PT) & 23 & 8 & $\mathrm{~A}, \mathrm{l}, \mathrm{MF}$ \\
\hline 9 & 40 & Male & M.Sc. & Australia & OT clinician & 9 & 6 & A \\
\hline 10 & 44 & Male & Ph.D. & Nigeria & Academia (PT) & 21 & 9 & A \\
\hline 11 & 52 & Male & M.Sc. & Nigeria & Academia (OT) & 13 & 10 & $\mathrm{~A}, \mathrm{l}, \mathrm{MF}$ \\
\hline 12 & 43 & Female & Ph.D. & Nigeria & Academia (PT) & 20 & 13 & $A, I$ \\
\hline 13 & 45 & Female & Ph.D. & Sweden & Academia and Private OT practice & 20 & $10+$ & $\mathrm{A}, \mathrm{I}, \mathrm{MF}$ \\
\hline 14 & 45 & Female & Ph.D. & Uganda & Academia (PT) & 12 & 6 & $\mathrm{~A}, \mathrm{I}, \mathrm{MF}$ \\
\hline 15 & 69 & Male & M.Sc & Nigeria & PT clinician & 38 & 21 & $\mathrm{~A}, \mathrm{l}, \mathrm{MF}$ \\
\hline
\end{tabular}

A Assessment, / Intervention, MF Monitoring, and Follow-up, CM Case Management, $R$ Researcher, OT Occupational therapist, PT Physiotherapist

strengths and weaknesses with regards to their ability to make accurate decisions about work performance, as well as a comprehensive review of the clients' work integration should be considered at the final phase of the RTW programme. Consensus was reached on all the components of the assessment phase with the exception of its duration. Majority of the experts agreed on the inclusion of general functional skills training $(n=11$, 84.62\%); prevocational skills training $(n=9,69.23 \%)$; and work hardening $(n=9,69.23 \%)$ in the WIP phase of the SReTWIP. The experts consented to all intervention components included within the WTP phase and Clients Full Participation in Worker Role phase as well as their expected durations (Table 4). The experts' responses to the duration and frequency of treatment sessions within the phases of the SReTWIP is presented in Fig. 2. Consensus was reached on four out of five suggested strategies for implementing the SReTWIP. There was also consensus on the time to commence the programme during stroke survivors' recovery continuum. However, no consensus was reached by the experts on the period during stroke rehabilitation continuum when RTW should be commenced. In the third round, consensus was reached on all of the reviewed intervention components of the SReTWIP. Table 5 summarises the results of the third round of the Delphi survey.

The developed SReTWIP is presented in Fig. 3. The SReTWIP comprised four interconnected phases of interventions that will span 12 weeks. The programme commences with an assessment phase (phase 1) where comprehensive work ability assessment, workplace ergonomic assessment and goal settings are conducted for the stroke survivor. The phase is to be initiated during out-patient rehabilitation, after the client is independent in performing ADL. The phase is to be conducted over a minimum of three to five sessions after which the WIT phase will commence. In the WIT phase, work and nonwork specific intervention are provided for the stroke survivors in the clinic. These include: general functional skills training, vocational counselling and career planning as well as prevocational skills training. The WIT phase is to be conducted over a minimum of 5 to 9 treatment sessions. When competency has been achieved in the second phase by the stroke survivor, the client proceeds to a third phase, which is the WTP phase. In this phase, other stakeholders in the RTW process are engaged. The interventions provided are both clinic and work based, to be conducted over a minimum of 8 treatment sessions of $60 \mathrm{~min}$ each. The final phase of the SReTWIP, Clients Full Participation in Worker Role, envisions that the stroke survivor would have achieved competencies in varying work aspects of the previous three phases. During this stage, the stroke survivor would be encouraged to undergo self-reflection on their ability to participate in their occupational role as a worker. The client then synthesizes and internalizes the actions undertaken and skills acquired during the previous phases. In addition, stroke survivors are encouraged to make decisions on strengths and weaknesses as well as choice of rehabilitation services best suited to 


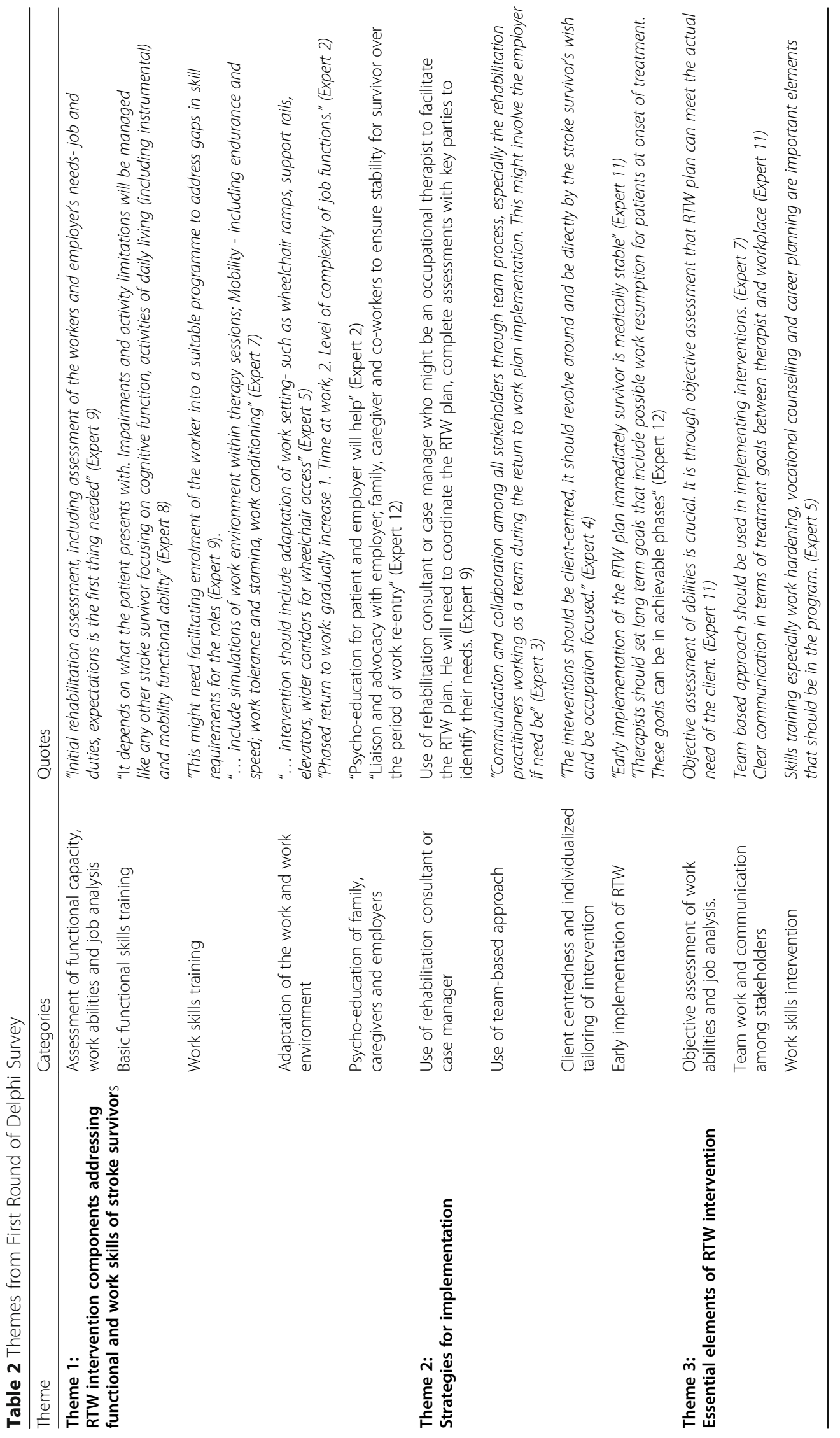




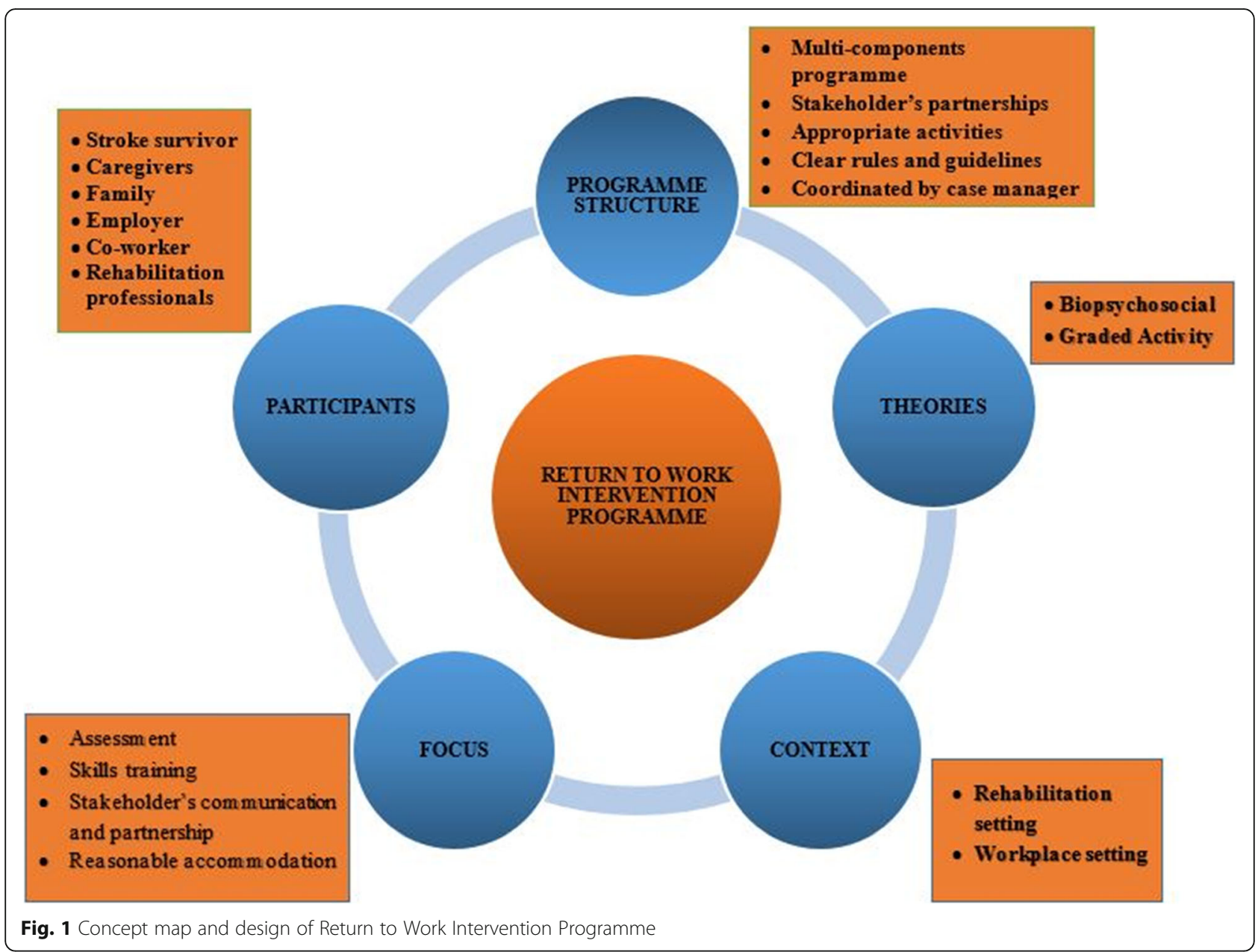

the specific skill that they require. The involvement of core rehabilitation specialist is gradually tapered during this phase. The entire process of the SReTWIP will be individually tailored to meet the needs of the stroke survivor and implemented by an IDT that will include the occupational therapists and physiotherapist as key members. Equally, the stroke survivor is expected to be involved in the decision making process throughout the duration of the SReTWIP. And finally, the programme is to be coordinated by a case manager who will be a member of the interdisciplinary team.

\section{Discussion}

The SReTWIP is the first VR programme that identified the essential RTW components and provided a clear pathway for implementing RTW intervention for stroke survivors. On completion of the Delphi study, minor changes were effected in the first three phases of the programme and in the programme implementation strategies. Firstly, the "duration" of the various phases were renamed to "frequency and duration" in order to accommodate for the timing (how long) and the numbers of sessions (how often) required for each phase of the programme. This provided clear information regarding the frequency of the interventions and served as a step for the proper quantification of the various intervention phases to ensure future fidelity assessment [17]. The panel of experts established the relevance of functional capacity evaluation, job analysis and workplace ergonomic assessment of the stroke survivor during VR. Comprehensive work assessment helps to determine the stroke survivors' eligibility for services as well as the nature and scope of interventions to be included during the subsequent phases of the SReTWIP [18]. Holistic understanding of the stroke survivor's work capacities and barriers is important for delivering the SReTWIP effectively. The inclusion of goal setting as an integral part of the assessment phase of the SReTWIP could enhance communication and collaboration within rehabilitation teams [19-21] as well as improve patient motivation and engagement in the other phases of the SReTWIP programme [22]. Although in most literature, goal 


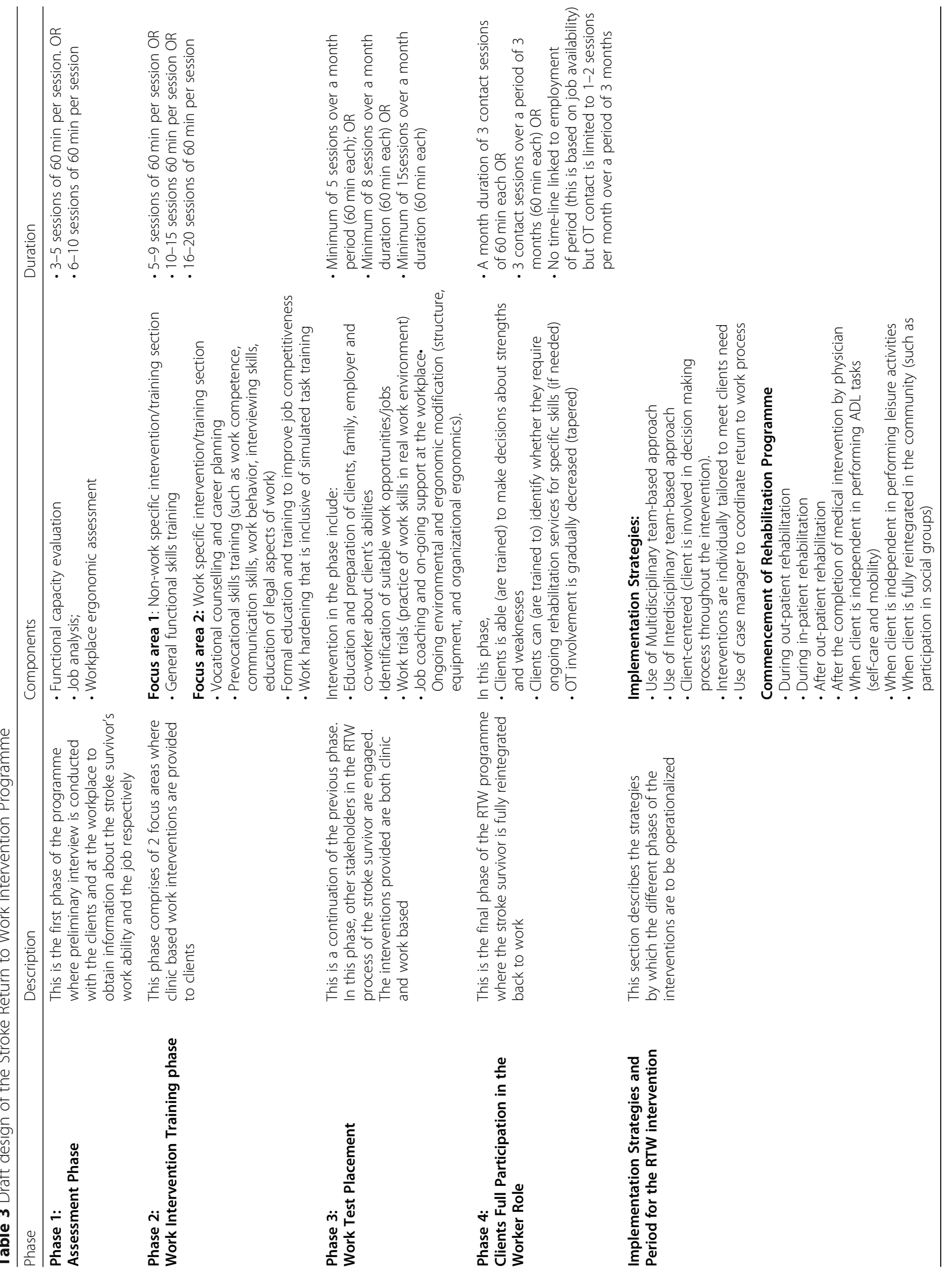


Table 4 Response of panel of experts to second round of Delphi survey

\begin{tabular}{|c|c|c|c|}
\hline Phase & $\begin{array}{l}\text { Agree } n \\
(\%)\end{array}$ & $\begin{array}{l}\text { Disagree } n \\
(\%)\end{array}$ & $\begin{array}{l}\text { Indifferent } \mathrm{n} \\
(\%)\end{array}$ \\
\hline \multicolumn{4}{|l|}{ Phase 1 components: Assessment } \\
\hline - Functional capacity evaluation & 13 & 0 & 0 \\
\hline - Job analysis & 13 & 0 & 0 \\
\hline -Workplace ergonomic assessment & 13 & 0 & 0 \\
\hline \multicolumn{4}{|l|}{ Phase 2 components: Work Intervention Training } \\
\hline \multicolumn{4}{|l|}{ Focus area 1: Non-work specific intervention/ training session } \\
\hline - In this focus area, general functional skills training are provided for the stroke survivor & $11(84.6)$ & $2(15.4)$ & $0(0.0)$ \\
\hline \multicolumn{4}{|l|}{ Focus area 2: Work specific intervention/training session } \\
\hline $\begin{array}{l}\text { - Prevocational skills training (such as work competence, communication skills, work behavior, interviewing skills, education } \\
\text { of legal aspects of work, commuting to and from work) }\end{array}$ & $9(69.2)$ & $2(15.4)$ & $2(15.4)$ \\
\hline - Vocational counselling and career planning & $8(61.5)$ & $1(7.7)$ & $4(30.8)$ \\
\hline - Formal education and training to improve job competitiveness & $6(46.1)$ & $3(23.1)$ & $4(30.8)$ \\
\hline - Work hardening that is inclusive of simulated task training & $9(69.2)$ & $2(15.4)$ & $2(15.4)$ \\
\hline \multicolumn{4}{|l|}{ Phase 3 components: Work Test Placement } \\
\hline - Education and preparation of clients, family, employer and co-worker about client's abilities & $9(69.2)$ & $0(0.00)$ & $4(30.8)$ \\
\hline - Identification of suitable work opportunities/jobs & $9(69.2)$ & $2(15.4)$ & $2(15.4)$ \\
\hline - Work trials (practice of work skills in real work environment) & $11(84.6)$ & $2(15.4)$ & $0(0.0)$ \\
\hline - Job coaching and on-going support at the workplace & $10(76.9)$ & $1(7.7)$ & $2(15.4)$ \\
\hline \multicolumn{4}{|l|}{ Phase 4 components: Clients Full Participation in the Worker Role } \\
\hline - Clients is able (are trained) to make decisions about strengths and weaknesses & $12(92.3)$ & $1(7.7)$ & $0(0.0)$ \\
\hline - Clients can (are trained to) identify whether they require ongoing rehabilitation services for specific skills (if needed) & $12(92.3)$ & $1(7.7)$ & $0(0.0)$ \\
\hline - Rehabilitation professional involvement is gradually decreased (tapered) & $12(92.3)$ & $1(7.7)$ & $0(0.0)$ \\
\hline - Clients is able (are trained) to make decisions about strengths and weaknesses & $12(92.3)$ & $1(7.7)$ & $0(0.0)$ \\
\hline \multicolumn{4}{|l|}{ Implementation Strategies of RTW intervention } \\
\hline - Use of Multidisciplinary team-based approach & $4(30.8)$ & $8(61.5)$ & $1(7.7)$ \\
\hline - Use of interdisciplinary team-based approach & $11(84.6)$ & $1(7.7)$ & $1(7.7)$ \\
\hline - Client-centered (client is involved in decision making process throughout the intervention) & $11(84.6)$ & $2(15.4)$ & $0(0.0)$ \\
\hline - Interventions are individually tailored to meet clients need & $11(84.6)$ & $2(15.4)$ & $0(0.0)$ \\
\hline - Use of case manager to coordinate return to work process & $9(69.2)$ & $3(23.1)$ & $1(7.7)$ \\
\hline \multicolumn{4}{|l|}{ When to commence the programme during stroke rehabilitation } \\
\hline - During out-patient rehabilitation & $7(53.8)$ & $4(30.8)$ & $2(15.4)$ \\
\hline - During in-patient rehabilitation & $7(53.8)$ & $5(38.5)$ & $1(7.7)$ \\
\hline - After out-patient rehabilitation & $8(61.5)$ & $3(23.1)$ & $2(15.4)$ \\
\hline - After the completion of medical intervention by physician & $8(61.5)$ & $2(15.4)$ & $3(23.1)$ \\
\hline \multicolumn{4}{|l|}{ When to commence the programme during recovery continuum } \\
\hline - When client is independent in performing ADL tasks (self-care and mobility) & $12(92.3)$ & $1(7.7)$ & $0(0.0)$ \\
\hline -When client is independent in performing leisure activities & $3(23.1)$ & $9(69.2)$ & $1(7.7)$ \\
\hline - When client is fully reintegrated in the community (such as participation in social groups) & $2(15.4)$ & $8(61.5)$ & $3(23.1)$ \\
\hline
\end{tabular}

setting during stroke rehabilitation has been generally referred to as a single activity that is isolated from other rehabilitation processes $[19,23,24]$. Plant and Tyson [25], on the contrary asserted that goal setting process as well as patient's assessment during stroke rehabilitation are clearly interlinked. The above authors suggested the integration of the two processes in long term post stroke rehabilitation.
Furthermore, the inclusion of non-work specific and work specific sections in the WIT phase were indicated by the experts. Intervention contents within this phase comprised vocational counselling and career planning, prevocational skills trainings work hardening and work simulation task training as well as general functional skills training which may be delivered as a single or multicomponent form. As work disability after stroke could 


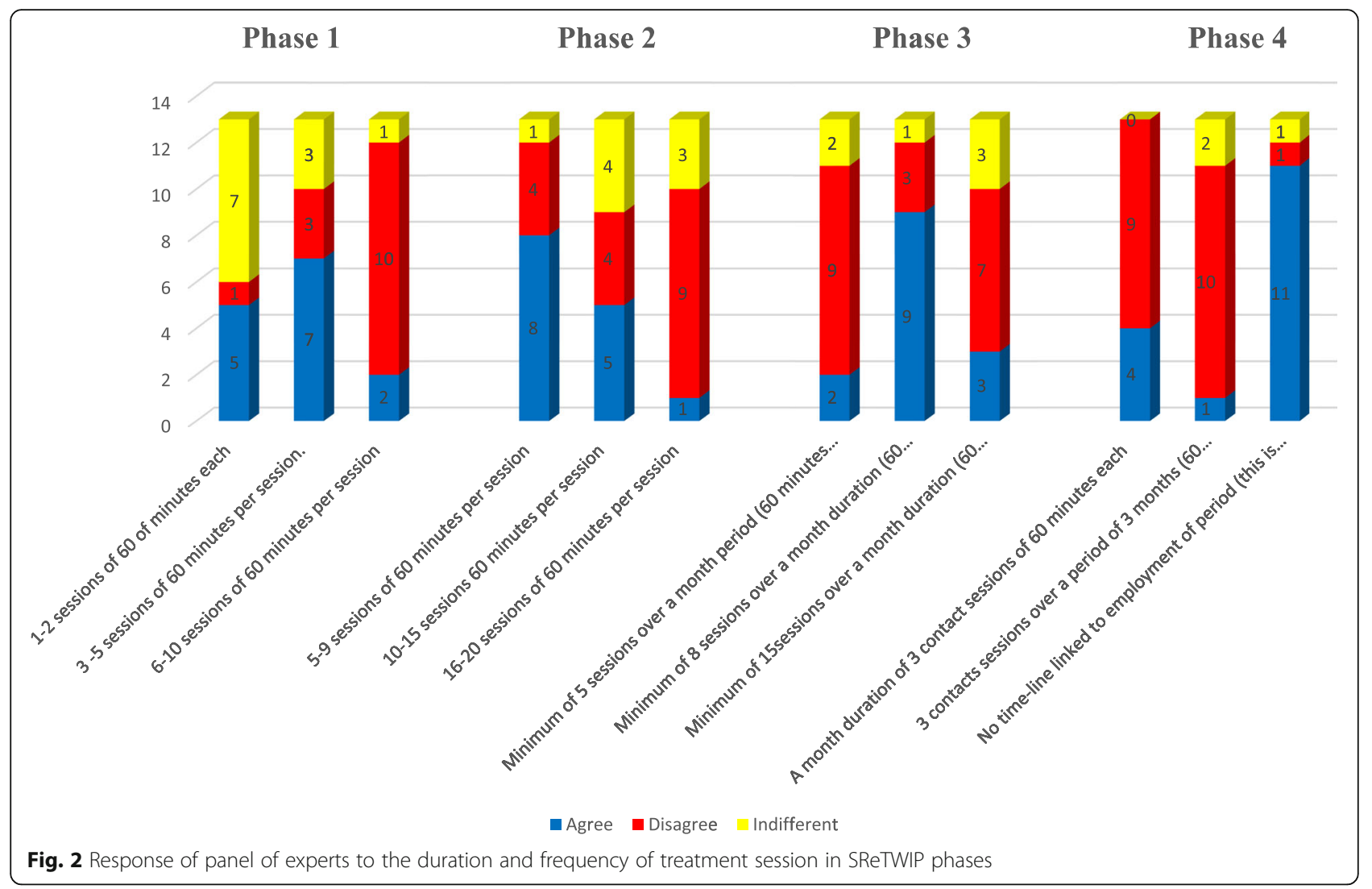

result from a combination of difficulties experienced at stroke survivor's personal and societal levels based on the biopsychosocial framework of the ICF [26], work skills training in the WIT phase will address skills deficit from the stroke event. It will further help to build selfconfidence and competence of the stroke survivor before re-entering the workplace [27]. On the other hand, formal education and training to improve job competitiveness was excluded as a component of the WIP phase. Although it was highlighted by the experts that upgrade of skill sets required for work performance may be needed, it was however opined that these would not be conducted by rehabilitation teams involved in the RTW process of the stroke survivor. Thus, formal education and upgrading of skill sets were excluded from the SReTWIP by the experts.

The WTP phase of the SReTWIP recognized the need for a fit between the work abilities of the worker and the job through work trials, identification of suitable work opportunities, ergonomic and environmental modification in order to encourage work participation [28]. Reasonable accommodation in the form of ergonomic and environmental modification provides opportunity for RTW efforts, especially in situations where restoration of deficits in work skills may otherwise not be possible.
Such ergonomic and environmental modification has been adduced to facilitate not only work resumption but also job retention among stroke survivors [29]. Similarly, job coaching, a one on one intensive support and feedback to achieve competence on the job by stroke survivors within the WTP phase could effectively enhance work retention [3].

With regards to the implementation strategies, the multi-disciplinary team-based approach (MDT) was excluded, as experts felt that the interdisciplinary approach (IDT) was more suited for delivering the RTW intervention. Although MDT has been associated with improvements in the quality of stroke care by policy makers and clinical guideline developers in the literature [30-33], considering the context in which the RTW would take place, the experts felt that the conceivable value of integrated team action may not be achieved using MDT. Rather the IDT was considered as a more practicable approach as it allows team members to perform activities toward a common goal such as RTW, and accept the additional obligation of group effort for clients. Disciplinary articulation provided within the IDT could have further informed the position taken by the experts since the IDT enables team members to have an understanding of each other's roles and identifies where 
Table 5 Response of panel of experts to third round of Delphi survey

\begin{tabular}{|c|c|c|}
\hline Items & $\mathrm{n}(\%)$ & Comments \\
\hline \multicolumn{3}{|l|}{ Duration of RTW Assessment phase } \\
\hline \multicolumn{3}{|l|}{ How many sessions? } \\
\hline - Minimum of $1-2$ sessions & $3(23.1)$ & \\
\hline - Minimum of 3-5 sessions & $10(76.9)$ & \\
\hline \multicolumn{3}{|c|}{ How long should each Assessment Session take? } \\
\hline$\cdot 30 \mathrm{~min}$ & $1(7.7)$ & \\
\hline • 45-60 & $12(92.3)$ & \\
\hline \multicolumn{3}{|l|}{ Duration of WIT phase } \\
\hline How many sessions? & & \multirow{3}{*}{$\begin{array}{l}\text { As RTW intervention is client-centred, the frequency and } \\
\text { duration of intervention will depend on personal and clinical } \\
\text { factors of the client. }\end{array}$} \\
\hline - Minimum of 5-9 sessions & $11(84.6)$ & \\
\hline - Minimum of $10-15$ sessions & $2(15.4)$ & \\
\hline \multicolumn{3}{|c|}{ How long should each Assessment session take? } \\
\hline$\cdot 30 \mathrm{~min}$ & $1(7.7)$ & \\
\hline$\cdot 45-60 \mathrm{~min}$ & $12(92.3)$ & \\
\hline \multicolumn{3}{|c|}{ Relevance of intervention components within WTP } \\
\hline \multicolumn{3}{|c|}{ Vocational counselling and career planning } \\
\hline - Relevant & $13(100.0)$ & \\
\hline - Not relevant & $0(0.0)$ & \\
\hline \multicolumn{3}{|c|}{ Formal education and training to improve job competitiveness } \\
\hline - Relevant & $9(69.2)$ & \\
\hline - Not Relevant & $4(30.8)$ & \\
\hline \multicolumn{3}{|c|}{ Implementation Period of the RTW intervention } \\
\hline \multicolumn{2}{|l|}{ During out-patient rehabilitation } & \multirow{3}{*}{$\begin{array}{l}\text { Essential to go side by side with other treatment schedules } \\
\text { at the onset }\end{array}$} \\
\hline - Yes & $12(92.3)$ & \\
\hline$\cdot$ No & $1(7.7)$ & \\
\hline \multicolumn{3}{|l|}{ After out-patient rehabilitation } \\
\hline$\cdot$ Yes & $3(23.1)$ & \\
\hline$\cdot$ No & $10(76.9)$ & \\
\hline \multicolumn{3}{|c|}{ After the completion of medical intervention by physician } \\
\hline - Yes & $4(30.8)$ & \\
\hline$\cdot$ No & $9(69.2)$ & \\
\hline
\end{tabular}

overlap occurs $[33,34]$. As IDT allows RTW team members to work as equals, with reverence for the expertise and knowledge provided by each team member, it will therefore facilitate a more cohesive and efficient approach to collaborative working among the RTW team when implementing the SReTWIP. Furthermore, IDT in stroke management has been attributed to ease prompt information exchange and facilitates early interventions, as well as an effective approach in longer term rehabilitation in community settings $[35,36]$. The use of case managers to oversee the SReTWIP was considered an important strategy in achieving the goals of the programme by the experts. VR coordinators and case managers have been acknowledged as vital players in the success of RTW process [3, 37]. Utilization of case managers when implementing the SReTWIP will ensure that the workplace is set as the core of RTW plan. With this, rehabilitation activities can be implemented and progressively centralized within the stroke survivors' workplace with a focus on the job to be returned to by the survivor [37].

\section{Conclusion}

The SReTWIP is the first step in developing a VR pathway that could ultimately enhance the RTW rates and quick resumption of the worker role of stroke survivors. 


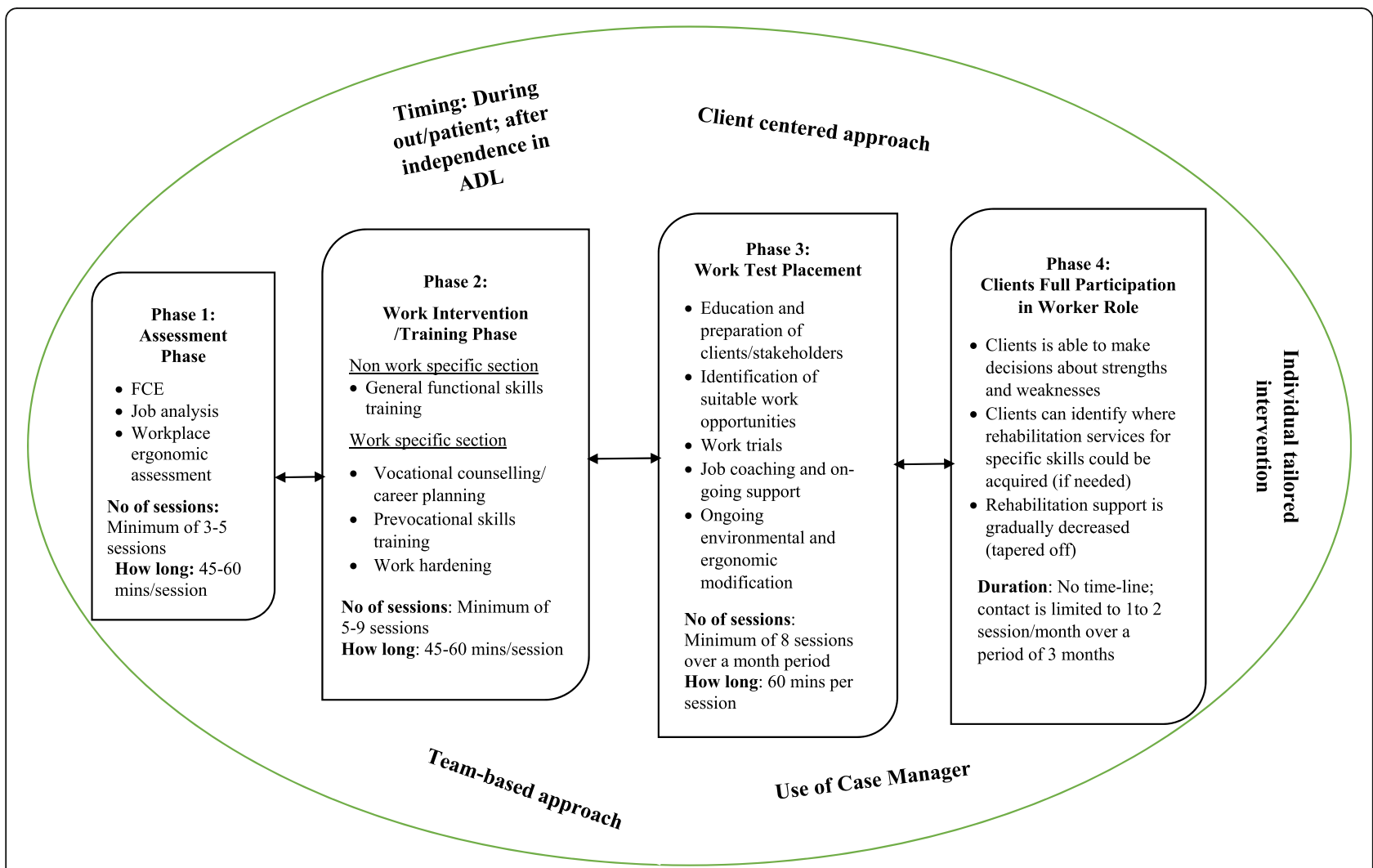

Fig. 3 Stroke Return to Work Intervention Programme (SReTWIP)

The stroke survivor can move along the different phases of the SReTWIP after achieving competency in a preceding phase. Future work will include a feasibility study with other key stakeholders involved in RTW such as employers, informal caregivers and the stroke survivors before its implementation.

\section{Abbreviations}

ICF: International Classification of Functioning, Disability and Health; IDT: Interdisciplinary Team; MDT: Multi-disciplinary Team; MSD: Musculoskeletal dysfunction; OT: Occupational therapist; PT: Physiotherapist; RTW: Return to Work; SReTWIP: Stroke Return to Work Intervention Programme; TBI: Traumatic Brain Injury; VR: Vocational rehabilitation; WIT: Work Intervention and Training; WTP: Work Test Placement

\section{Acknowledgements}

The authors acknowledge the contributions of Dr. Jocelyn Harris, an associate professor at the School of Rehabilitation Sciences, McMaster University, Ontario, Canada. Dr. Harris was the research adviser of OAO during his doctoral fellowship at McMaster University.

\section{Authors' contributions}

The authors OAO, SMS and AR participated in the design, planning, development, analysis, interpretation of the result, critical review and writing of the manuscript. All authors read and approved the final manuscript.

\section{Authors' information}

OAO is a lecturer in the Occupational Therapy Programme of the Department of Medical Rehabilitation, Obafemi Awolowo University, Nigeria and a Research affiliate at the Department of Occupational Therapy, University of the Western Cape, South Africa.
SMS is a professor of Occupational Therapy and the Head of Department, Department of Occupational Therapy, University of the Western Cape, South Africa.

AR is a Professor of Physiotherapy and the Dean, Faculty of Community and Health Sciences, University of the Western Cape, South Africa.

\section{Funding}

The writing of the manuscript was supported by the University of the Western Cape (UWC), Writing Fellowship Bursary. Research fellowship of OA was supported by the World Bank Robert S. McNamara Doctoral Fellowship. Financial support for the doctoral programme of OA was provided by the Nigerian Tertiary Education Trust fund (TETFund).

\section{Availability of data and materials}

The datasets used and/or analyzed during the current study are available from the corresponding author on reasonable request.

\section{Ethics approval and consent to participate}

The Research Ethics and Higher Degrees Committee of the University of the Western Cape, South Africa as well as the Health Research and Ethics Committee of the Institute of Public Health, Obafemi Awolowo University, Nigeria, gave approval for this study. Also, written consent was provided by the participants of this study.

\section{Consent for publication}

Not Applicable.

\section{Competing interests}

The authors declare that they have no competing interests.

\section{Author details}

${ }^{1}$ Departments of Occupational Therapy, Faculty of Community and Health Sciences, University of the Western Cape, Cape Town, South Africa.

${ }^{2}$ Departments of Medical Rehabilitation, College of Health Sciences, Obafemi 
Awolowo University, lle-lfe, Nigeria. ${ }^{3}$ Department of Physiotherapy, Faculty of Community and Health Sciences, University of the Western Cape, Cape Town, South Africa.

Received: 27 September 2019 Accepted: 28 February 2020

Published online: 13 March 2020

\section{References}

1. Feigin VL. Anthology of stroke epidemiology in the 20th and 21st centuries: assessing the past, the present, and envisioning the future. Int J Stroke. 2019;14(3):223-37.

2. Katan M, Luft A. Global burden of stroke. In: Seminars in neurology; 2018. p. 208-11.

3. van Velzen JM, van Bennekom CA, van Dormolen M, Sluiter JK, FringsDresen $\mathrm{MH}$. Evaluation of the implementation of the protocol of an early vocational rehabilitation intervention for people with acquired brain injury. Disabil Rehabil. 2016;38(1):62-70.

4. Escorpizo R, Ekholm J, Gmünder HP, Cieza A, Kostanjsek N, Stucki G. Developing a core set to describe functioning in vocational rehabilitation using the international classification of functioning, disability, and health (ICF). J Occup Rehabil. 2011;20(4):502-11.

5. Krupa T, Chen SP, Carter G. Serious mental illness, vocational rehabilitation, and employment. In: Handbook of Vocational Rehabilitation and Disability Evaluation. Cham: Springer; 2015. p. 335-54.

6. Soeker MS. The development of the model of occupational self efficacy: an occupational therapy practice model to facilitate returning to work after a brain injury. Work. 2012;43(3):313-22. https://doi.org/10.3233/WOR-2012-1412

7. van Beurden KM, Vermeulen SJ, Anema JR, van der Beek AJ. A participatory return-to-work programme for temporary agency workers and unemployed workers sick-listed due to musculoskeletal disorders: a process evaluation alongside a randomized controlled trial. J Occup Rehabil. 2012;22(1):127-40. https://doi.org/10.1007/s10926-011-9314-4

8. Olaoye OA, Soeker MS, Rhoda A. Predictors of work resumption among stroke survivors in south-west nigeria. Hong Kong J Occup Ther. 2019.

9. Olaoye OA, Harris J, Soeker MS, Rhoda A. Exploration of return to work interventions for stroke survivors: A scoping review. J Vocat Rehabil. 2019.

10. Arksey H, O'Malley L. Scoping studies: towards a methodological framework. Int J Soc Res Methodol. 2005:8(1):19-32. https://doi.org/10.1080/ 1364557032000119616

11. Eldredge LK, Markham CM, Ruiter RA, Kok G, Parcel GS. Planning health promotion programmes: an intervention mapping approach. 4th ed. San Francisco: Wiley; 2016.

12. Hasson F, Keeney S, McKenna H. Research guidelines for the Delphi survey technique. J Adv Nurs. 2000;32(4):1008-15. https://doi.org/10.1046/j.13652648.2000.t01-1-01567.x

13. Delbecq $A L$, Van de Ven $A H$, Gustafson $D H$. Group techniques for program planning. A guide to nominal group and Delphi processes. 1st ed. Glenview: Scott, Foresman and Company; 1975.

14. Salkind N. Encyclopedia of research design; 2010.

15. Okoli C, Pawlowski SD. The Delphi method as a research tool: an example, design considerations and applications. Inf Manag. 2004;42(1):15-29 Available from: http://linkinghub.elsevier.com/retrieve/pii/S0378720603001794.

16. Corbin JM, Strauss AL. Basics of qualitative research : techniques and procedures for developing grounded theory. 3rd ed. Los Angeles: Sage Publications; 2008.

17. DeJong G, Horn SD, Gassaway JA, Slavin MD, Dijkers MP. Toward a taxonomy of rehabilitation interventions: using an inductive approach to examine the "black box" of rehabilitation 11 No commercial party having a direct financial interest in the results of the research supporting this article has or will confer. Arch Phys Med Rehabil. 2004:85(4):678-86 Available from: http://linkinghub.elsevier.com/retrieve/pii/S000399930301013X.

18. van Velzen JM, van Bennekom CA, Sluiter JK, Frings-Dresen MH. Early vocational rehabilitation after acquired brain injury: a structured and interdisciplinary approach. J Vocational Rehabil. 2015;42(1):31-40. https://doi. org/10.3233/JVR-140725

19. Levack WM, Weatherall M, Hay-Smith EJC, Dean SG, McPherson K, Siegert RJ et al. Cochrane Database Syst Rev. 2015. https://doi.org/10.1002/14651858. CD009727.pub2.

20. Rosewilliam S, Roskell CA, Pandyan A. A systematic review and synthesis of the quantitative and qualitative evidence behind patient-centred goal setting in stroke rehabilitation. Clin Rehabil. 2011;25(6):501-14 Available from: http://journals.sagepub.com/doi/10.1177/0269215510394467.
21. Sugavanam T, Mead G, Bulley C, Donaghy M, van Wijck F. The effects and experiences of goal setting in stroke rehabilitation - a systematic review. Disabil Rehabil. 2013;35(3):177-90 Available from: http://www.tandfonline. com/doi/full/10.3109/09638288.2012.690501.

22. Alanko T, Karhula M, Kröger T, Piirainen A, Nikander R. Rehabilitees perspective on goal setting in rehabilitation - a phenomenological approach. Disabil Rehabil [Internet]. 2019;41(19):2280-8. Available from: https://www.tandfonline.com/doi/full/10.1080/09638288.2018.1463398.

23. Lloyd A, Bannigan K, Sugavanam T, Freeman J. Experiences of stroke survivors, their families and unpaid carers in goal setting within stroke rehabilitation. JBI Database System Rev Implement Rep. 2018;16(6):1418-53 Available from: https://doi.org/10.1080/09638288.2018.1463398.

24. Hartigan I. Goal setting in stroke rehabilitation: part 1. Br J Neurosci Nurs. 2012;8(2):65-9 Available from: http://www.magonlinelibrary.com/doi/10.12 968/bjnn.2012.8.2.65.

25. Plant S, Tyson SF. A multicentre study of how goal-setting is practised during inpatient stroke rehabilitation. Clin Rehabil. 2018;32(2):263-72 Available from: http://journals.sagepub.com/doi/10.1177/0269215517719485.

26. Finger ME, Escorpizo R, Glässel A, Gmünder HP, Lückenkemper M, Chan C, Fritz J, Studer U, Ekholm J, Kostanjsek N, Stucki G. ICF Core set for vocational rehabilitation: results of an international consensus conference. Disabil Rehabil. 2012;34(5):429-38. https://doi.org/10.3109/09638288.2011.608145.

27. Cancelliere C, Cassidy JD, Colantonio A. Specific disorder-linked determinants: traumatic brain injury. In: Handbook of Work Disability. New York: Springer; 2013. p. 303-14

28. Solovieva TI, Dowler DL, Walls RT. Employer benefits from making workplace accommodations. Disabil Health J. 2011;4(1):39-45. https://doi. org/10.1016/j.dhjo.2010.03.001.

29. Culler KH, Wang YC, Byers K, Trierweiler R. Barriers and facilitators of return to work for individuals with strokes: perspectives of the stroke survivor, vocational specialist, and employer. Top Stroke Rehabil. 2011;18(4):325-40. https://doi.org/10.1310/tsr1804-325

30. Clarke DJ. The role of multidisciplinary team care in stroke rehabilitation. Prog Neurol Psychiatry. 2013;17(4):5-8 Available from: http://doi.wiley.com/1 0.1002/pnp.288.

31. Harris R, Sims S, Hewitt G, Joy M, Brearley S, Cloud G, et al. Interprofessional teamwork across stroke care pathways: Outcomes and patient and carer experience. Final Rep Natl Inst Heal Res (NIHR), Serv Deliv Organ Program. 2013;(February).

32. Intercollegiate Stroke Working Party. National clinical guideline for stroke. 2012.

33. Reeves S, Lewin S, Espin S, Zwarenstein M. Interprofessional Teamwork for Health and Social Care. Partnership Working in Action. Chichester: Wiley Blackwell; 2010. p. 1-191.

34. McCallin A. Factors influencing team working and strategies to facilitate successful collborative teamwork. N Z J Physiother. 2009;37(2):62.

35. Clarke DJ. Achieving teamwork in stroke units: the contribution of opportunistic dialogue. J Interprof Care. 2010;24(3):285-97 Available from: https://doi.org/10.3109/13561820903163645. http://www.tandfonline.com.

36. Clarke D, Forster A. Improving post-stroke recovery: the role of the multidisciplinary health care team. J Multidiscip Healthc. 2015:8:433-442. https://doi.org/10.2147/JMDH.S68764.

37. Schwarz B, Claros-Salinas D, Streibelt M. Meta-synthesis of qualitative research on facilitators and barriers of return to work after stroke. J Occup Rehabil. 2018;28(1):28-44.

\section{Publisher's Note}

Springer Nature remains neutral with regard to jurisdictional claims in published maps and institutional affiliations. 